Article

\title{
Information Entropy Evolution for Groundwater Flow System: A Case Study of Artificial Recharge in Shijiazhuang City, China
}

Wei Xu ${ }^{1,2}$ and Shanghai Du ${ }^{1,2, *}$

1 Key Laboratory of Groundwater Resources and Environment, Ministry of Education, Jilin University, Changchun 130021, China; E-Mail: xuwei7537@163.com

2 Institute of Water Resources and Environment, Jilin University, Changchun, China

* Author to whom correspondence should be addressed; E-Mail: dushanghai@jlu.edu.cn;

Tel./Fax: +86-0431-88502595.

Received: 30 April 2014; in revised form: 17 July 2014 / Accepted: 28 July 2014 /

Published: 5 August 2014

\begin{abstract}
The groundwater flow system is typical dissipative structure system, and its evolution can be described with system information entropies. The information entropies of groundwater in Shijiazhuang City had been calculated between 1960 and 2005, and the results show that the entropies have a decreasing trend throughout the research period, and they can be divided into our stages based on the groundwater flow system entropy variation as follows: entropy steady period (1960-1965), entropy decreasing period (1965-1980), entropy increasing period (1980-1995) and secondary entropy decreasing period (1995-2005); understanding the major and significant driving the pattern changing forces of groundwater levels is essential to groundwater management,. A new method of grey correlation analysis has been presented, and the results show that, the grey correlation grade between groundwater flow system information entropies and precipitation series is $\gamma_{01}=0.749$, the grey correlation grade between groundwater flow system information entropies and groundwater withdrawal series is $\gamma_{02}=0.814$, as the groundwater withdrawal is the main driving force of groundwater flow system entropy variation; based on the numerical simulation results, information entropy increased with artificial recharge, and a smaller recharge water volume would enhance the information entropy drastically, but then doubled water would not increase the information correspondingly, which could be useful to assess the health state of groundwater flow systems.
\end{abstract}


Keywords: dissipative structure; entropy; grey correlation grade; groundwater flow system evolution; artificial recharge; Shijiazhuang City

\section{Introduction}

As one of the most important concept in modern science, entropy theory is becoming more and more popularly used. Especially after 1948, when Shannon put forward the concept of "information entropy (IE)", the entropy concept has broken the limits of the thermodynamics and statistical physics fields, and is now extensively used in natural and social science fields, having become one of the most important concepts of modern science [1].

As the concept of information entropy has been universally used, many geographers have done many interesting works in "field entropy" [2-5]. Analyzing of the thermodynamic conduction equation by analogy, information entropy could be used in the study of surface material movements, and geographical field entropy could be calculated by information theory, confirming that geographical system evolution has an "arrow of time" characteristic [2]. Dissipative structure theory, synergetic theory and mutation theory could be used in the study of system evolution according to this sound academic basis [6]. As one of the most important information carriers on the Earth's surface and subsurface, the groundwater flow system shares similar material and energy transmission characteristics with the thermodynamic system, so the application of information entropy theory to the study of groundwater system evolution has a good theoretical basis.

Works on calculation methods, mechanisms, and factors influencing geographic parameter distributions have been systemically done by geographers [1]. A "dissipative structure" is a non-equilibrium system that is far from a system equilibrium state, and should be supported by continuous materials inputs and outputs in open systems. The dissipative structure characteristics of the groundwater flow system have been discussed in detail, and human activity is a significant factor in the groundwater flow system evolution [7,8]. In contrast with heat flow processes, one can analyze the application feasibility of information entropy in groundwater flow system, and the calculative methodology has been given based on flux - hydraulic gradient curves and area - water level curves, but there is a lack of a specific examples for validation [6], and application examples are necessary for the study of information entropy in groundwater flow system evolution.

Groundwater has been the main water resource of Shijiazhuang City for a long time, and the overdrafting and mismanagement of the groundwater resources has formed a depression cone in the center of Shijiazhuang City, where precipitation and human excavation are the main factors in the evolution of the groundwater flow system [9-11]. In this study, the groundwater flow systems of Shijiazhuang City between 1960 and 2005 have been chosen as examples, the information entropies of groundwater flow system have been calculated, and the groundwater flow systems information entropy variation and their main factors between 1960 and 2005 have been discussed.

Understanding the major and significant driving forces driving groundwater level change patterns is essential to groundwater management [12]. The traditional sensitivity analysis assumes that one specific factor is varied while all others are fixed, and called as "change-one-factor-at-a-time method". 
However, the simplicity of the method may yield unreliable results and inadequate conclusions because factors are uncertain, so a new method of grey correlation analysis had been presented, which addresses some of the shortcomings of the traditional method $[13,14]$. The method has been extensively applied across many areas, such as auto control design, water resource development, hydroelectric generation scheduling and environmental management [15-18].

\section{Study Area}

Shijiazhuang City is the capital of Hebei Province, China (Figure 1), which is located on the alluvial fan of the Hutuo River, and a surface water reservoir named Huangbizhuang located at the outlet of Hutuo River from Taihang Mountain, and it is the most influential hydraulic project in Shijiazhuang City. The Hutuo River bed downstream of the reservoir is dry the whole year. except during the flood season, when it could receive surplus water from the upstream reservoir and recharge the aquifer.

Figure 1. Location of the study area.

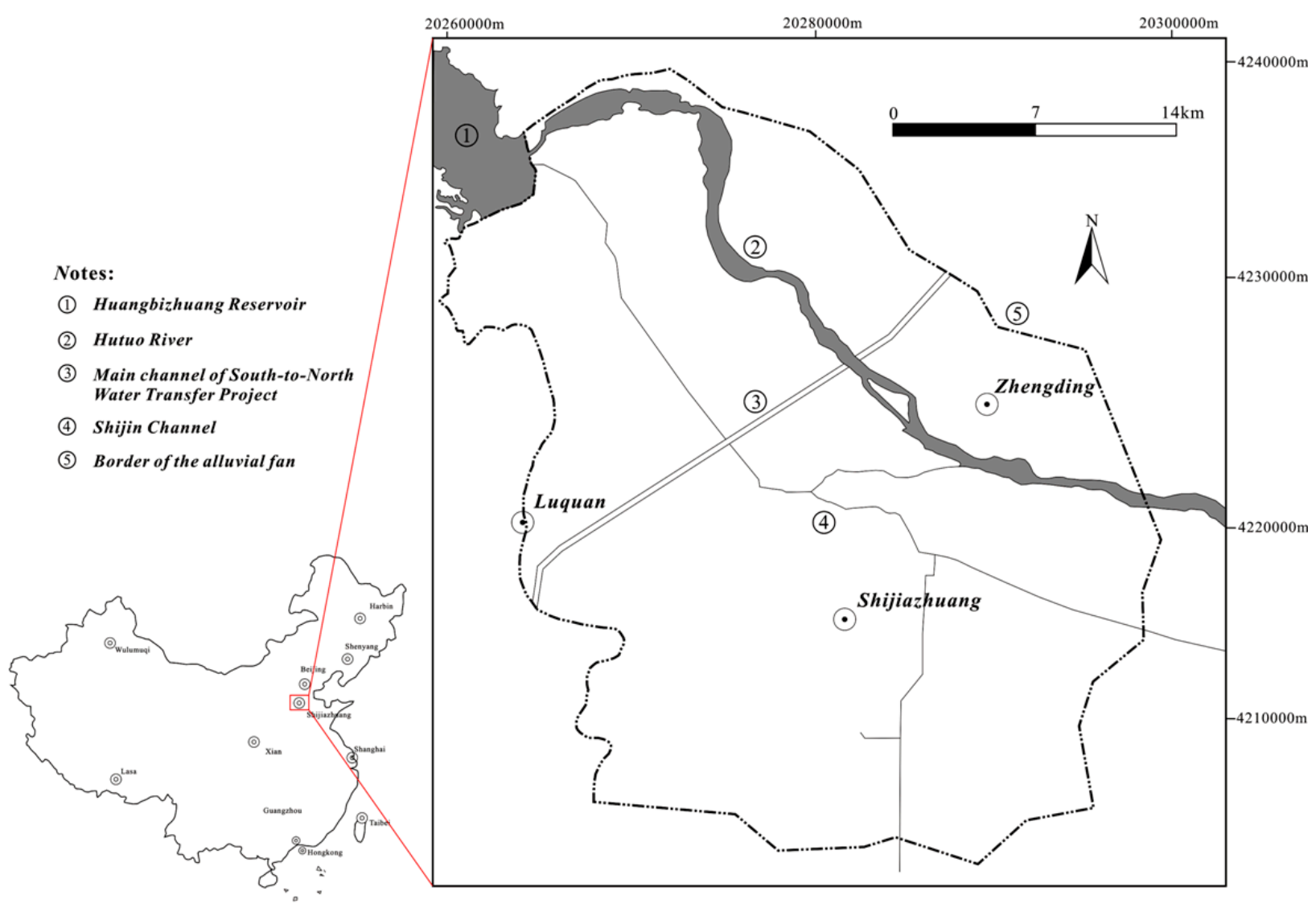

There is an average annual precipitation of $493 \mathrm{~mm}$, over $80 \%$ of which is concentrated in the flood season from June to September. The maximum precipitation was $1097 \mathrm{~mm}$, which occurred in 1996, and the minimum precipitation was $232 \mathrm{~mm}$, which occurred in 1972. The average surface water evaporation was $1100 \mathrm{~mm}$.

There are two hydrogeological units through the quaternary aquifer of Shijiazhuang City, the upper unit is a Holocene-upper and middle Pleistocene phreatic aquifer, which is the main exploited aquifer 
layer in study area, the lower one is a lower Pleistocene confined aquifer, which is confined with a continuous clay layer between the upper and lower layers.

Groundwater is the sole water resource of Shijiazhuang City and the groundwater level as descended drastically, along with a continuous drought after 2000, while the area of the cone of depression enlarged to $436.50 \mathrm{~km}^{2}$ and the depth of the groundwater level to the ground surface at the center of the cone of depression was $52.40 \mathrm{~m}$ in 2006. Groundwater overdrafting has greatly impacted the local groundwater flow system $[19,20]$.

\section{Methodology}

\subsection{Field Entropy Methodology}

The concept of information as "entropy" had been expressed since the mathematical formula for the concept is similar to the entropy function defined in statistical mechanics [21]. According to the given definition of information entropy, the information entropy of continuous random variables can be defined as following formula:

$$
H=-\int_{-\infty}^{+\infty} g(x) \ln g(x) d x
$$

where $\mathrm{H}$ refers to the information entropy of the continuous random variable, $g(x)$ is represented as a continuous random distribution function.

According to the geographical parameters distribution curve, a field entropy calculation method had been given [3]. In this study, a density function for groundwater flow system is given as follows:

$$
g(x)=\left\{\begin{array}{cccc}
f(x) / \int_{0}^{1} f(x) d x & 0 \leq x \leq 1 \\
0 & x<0 & \text { or } & x>1
\end{array}\right.
$$

where, $x$ refers to groundwater levels.

Combining Equations (1) and (2), the information entropy could be defined as following:

$$
\begin{aligned}
H & =-\int_{-\infty}^{+\infty} g(x) \ln g(x) d x \\
& =-\int_{0}^{1}\left[f(x) / \int_{0}^{1} f(x) d x\right] \ln \left[f(x) / \int_{0}^{1} f(x) d x\right] d x \\
& =-\int_{0}^{1}[f(x) / S] \ln [f(x) / S] d x
\end{aligned}
$$

where, S refers to Strahler integral [22], a famous formula which is defined as $S=\int_{0}^{1} f(x) d x$, and worldwide used in the geomorphology quantitative study, and we used this formula in the study of groundwater flow systems.

According to the Strahler integral, $(1-x)$ could be used to fit area-elevation function:

$$
\int_{0}^{1} f(x) d x=\int_{0}^{1}(1-x)^{a} d x=\frac{1}{1+a}=S
$$

Combining Equations (3) and (4), the information entropy could be defined farther as follows: 


$$
\begin{aligned}
H & =-\int_{0}^{1}[f(x) / S] \ln [f(x) / S] d x \\
& =-\left[\ln (1+a)-\frac{1}{1+a}\right] \\
& =1+\ln S-S
\end{aligned}
$$

Therefore, the groundwater flow system entropy could be calculated by Strahler integral, which results from groundwater level contour line map. The methodology of groundwater flow system information entropy based on groundwater level contour map could be done according to following steps:

(1) Calculate the areas between each contour line and the highest groundwater level contour line;

(2) Calculate the elevation difference between each groundwater contour line and the lowest groundwater level contour line;

(3) Assign the total area as A, the difference between the highest and the lowest groundwater level contour line as $B, x=a / A, y=b / B$ as the two coordinates respectively, the Strahler integral values and information entropies could be acquired according to a series of $(a, b)$, which can draw the Strahler integral curve.

\subsection{Grey Correlation Analysis}

The grey correlation analysis could be used to determinate the orders of factors for the data sequence variation, especially for the hydrological factors for the variations of recharge water [23]. According to "grey data processing", two kinds of methodologies could be used for the normalization of the original data in the study:

$$
\begin{aligned}
& x_{i}^{*}(k)=\frac{x_{i}(k)-\min x_{i}(k)}{\max x_{i}(k)-\min x_{i}(k)} \\
& x_{i}^{*}(k)=\frac{\max x_{i}(k)-x_{i}(k)}{\max x_{i}(k)-\min x_{i}(k)}
\end{aligned}
$$

The difference between these two methodologies are "the larger the better" and "the smaller the better", respectively. After the processing, the grey correlation coefficient could be calculated by the following equation $[17,18]$ :

$$
\gamma\left(x_{0}^{*}(k), x_{i}^{*}(k)\right)=\frac{\Delta_{\min }+\xi \Delta_{\max }}{\Delta_{0 i}(k)+\xi \Delta_{\max }}
$$

where, $\xi$ is the distinguishing coefficient, $\xi \in(0,1)$.Generally $\xi$ is taken as $0.5 . \Delta_{0 i}(k)$ is the sequence of deviation of the reference sequence $x_{0}^{*}(k)$ from the sequence $x_{i}^{*}(k)$ for comparison:

$$
\begin{gathered}
\Delta_{0 i}(k)=\left|x_{0}^{*}(k)-x_{i}^{*}(k)\right| \\
\Delta_{\max }=\max _{\forall j \in i} \max _{\forall k}\left|x_{0}^{*}(k)-x_{j}^{*}(k)\right| \\
\Delta_{\min }=\min _{\forall j \in i} \min _{\forall k}\left|x_{0}^{*}(k)-x_{j}^{*}(k)\right|
\end{gathered}
$$

An average of the grey correlation coefficients named grey correlation grade could be determined by the following equation [13]: 


$$
\Gamma_{i}\left(x_{0}^{*}, x_{i}^{*}\right)=\frac{1}{n} \sum_{k-1}^{n} \gamma\left(x_{0}^{*}(k), x_{i}^{*}(k)\right)
$$

The grey correlation grade could be used to analyze the relationship between two data sequences, and the results could also be used to modify the domain impact factors for the groundwater level and water chemistry variation in groundwater [17,24,25].

\section{Results and Discussion}

\subsection{Entropy Variation during 1960-2005}

The groundwater flow system is a complex combination, which is controlled by natural and human factors, and has 4-D spatial and temporal distribution characteristics [26]. According to dissipative structure theory, material and energy exchange between open systems and their environment, and in the irreversible process system, the system entropy change dS is composed of two parts:

$$
\mathrm{d} S=\mathrm{d}_{i} S+\mathrm{d}_{e} S
$$

where $\mathrm{d} S$ refers to the system entropy change of an open system; $\mathrm{d}_{i} S$ represents the system entropy production during irreversible processes, and it always increases the system entropy is positive; $\mathrm{d}_{e} S$ is the system entropy flow provided by the environment, when the material and energy exchange between systems and their environment is conducive to the system ordering, $\mathrm{d}_{e} S$ is negative, so when the total entropy decreases, or $\mathrm{d}_{e} S$ is positive, the total entropy increases as a result.

Before the 1960s groundwater excavation density in Northern China was not so high as today's, and there was a steady balance between groundwater recharge and discharge, so the groundwater flow system information entropy change $\mathrm{d}_{e} S$, which is input from the environment, offset the entropy changes within the groundwater flow system $\mathrm{d}_{i} S$, the groundwater flow system information entropy change $\mathrm{d} S=0$, and information entropy values remained in steady state. After the $1970 \mathrm{~s}$, due to the rapid socio-economic development with the resulting rapid increase in demand for water resources, groundwater excavation has greatly changed the regional groundwater flow system structures and function. Although the increased hydraulic gradient induces groundwater recharge, groundwater flow system information entropy $\mathrm{d}_{i} S$ increases as a result, but groundwater excavation with human activity makes the information entropy output $\mathrm{d}_{e} S$ larger and the $\mathrm{d}_{i} S$, groundwater flow system information entropy declines continually; when the $\mathrm{d}_{i} S$ equals the $\mathrm{d}_{e} S$, which is inspired by increasing excavation, the groundwater flow system reaches a balanced state again, and a dissipative structure forms. Dissipative structure theory and information entropy theory could be applied in the study of groundwater flow system information evolution.

In this study, groundwater level contour maps between 1960 and 2005 have been chosen for groundwater flow system information entropy analysis. Groundwater flow system information entropies have been calculated by the method described above, and a relationship curve between groundwater system entropies and time has been mapped (Figure 2). From the figure, there is a vivid phenomenon that groundwater flow system information entropy values exhibit a decreasing trend between 1960 and 2005, but fluctuation occurred in part, and four stages of groundwater flow system information entropy could be observed as follows: 
(1) Between 1960 and 1965, groundwater excavation in Shijiazhuang City is not as high as today's and abundant precipitation made the regional groundwater flow system be in a balanced state between groundwater recharge and discharge. There was little fluctuation of groundwater level, close to the natural groundwater flow state, and the system is steady, $\mathrm{d} S \approx 0$, and the groundwater flow system information entropies vary around -0.13 ;

(2) Between 1965 and 1980, with the rapid social and economic development, groundwater excavation increased year by year, combined with decreased precipitation, causing an increasing imbalance between groundwater recharge and discharge, a regional cone of depression had formed, expanded and deepened rapidly, and these factors broke the previous steady-state, changing the original groundwater flow state greatly; the entropy change $\mathrm{d}_{e} S$ increased over $\mathrm{d}_{i} S$, and since $\mathrm{d} S<0$, the groundwater flow system information entropies decreased to -0.30 ;

(3) Between 1980 and 1995, concerning with the environmental geological problems inspired by groundwater excavation, a planned groundwater excavation at Shijiazhuang City was put into effect, and this effectively reduced the rates of groundwater level decline, slowing down the extended speed of the cone of depression, and the local flooding effectively recharged the groundwater in 1988, alleviating the long-term negative balance state; the groundwater flow system information entropy change $\mathrm{d}_{e} S$ decreased less than $\mathrm{d}_{i} S$, and since $\mathrm{d} S>0$, the groundwater flow system information entropies increased to -0.20 ;

(4) Between 1995 and 2005, although the groundwater excavation varied to a small degree, the successive years of drought, decreasing the groundwater recharge, and the reinforcement project of the Huangbizhuang secondary dam reducing the effective recharge of groundwater further, made the groundwater flow system information entropy change $\mathrm{d}_{e} S$ increase over $\mathrm{d}_{i} S$ again, and the groundwater flow systems information entropy was dramatically reduced to -0.35 .

Figure 2. Information entropies variation in Shijiazhuang City between 1960 and 2005.

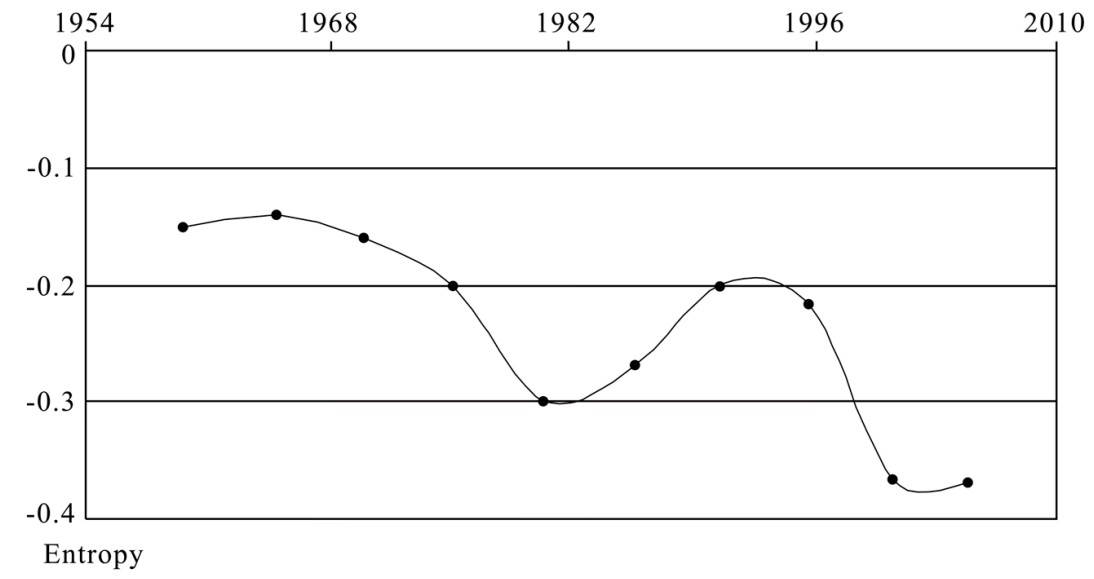

From the discussion above, the abnormal fluctuations of factors, such as the groundwater recharge, runoff and discharge, affected the relationship between $\mathrm{d}_{i} S$ and $\mathrm{d}_{e} S$. However, excavation and mismanagement of the groundwater resource, and groundwater flow system information entropies show a decreasing trend, and short-term fluctuations of groundwater recharge or discharge will result in partial entropy fluctuations. 


\subsection{Factor Analysis for Entropy Evolution}

Former studies show that the main driving forces of groundwater flow system evolution in Shijiazhuang City are precipitation and groundwater withdrawal [8,9], and a grey correlation analysis was used to identify the most important driving force of the regional groundwater flow system information entropy variation.

Taking the entropy variation speed, average precipitation and groundwater excavation series of each calculation period between 1960 and 2005 as the three variables in Table 1, a grey correlation analysis has been done. The results show that the grey correlation grade between groundwater flow system information entropies and precipitation is $\gamma_{01}=0.749$, and the grey correlation grade between groundwater flow system information entropies and groundwater withdrawal is $\gamma_{02}=0.814$, as the groundwater excavation is the main driving force of groundwater flow system information entropy variation.

Table 1. Information entropy of groundwater system and average precipitation, average groundwater abstraction between 1960 and 2005.

\begin{tabular}{cccc}
\hline Year & $\begin{array}{c}\text { Precipitation } \\
{[\mathbf{m m}]}\end{array}$ & $\begin{array}{c}\text { Groundwater Excavation } \\
{\left[\mathbf{1 0}^{\mathbf{8}} \mathbf{~ m}^{\mathbf{3}}\right]}\end{array}$ & $\begin{array}{c}\text { Entropy Variation } \\
{[\mathbf{\Delta H}]}\end{array}$ \\
\hline $1960-1965$ & 677.12 & 0.6208 & -0.0004 \\
$1965-1970$ & 437.52 & 0.7269 & -0.00328 \\
$1970-1975$ & 475.38 & 1.5872 & -0.01156 \\
$1975-1980$ & 519.56 & 2.0378 & -0.01884 \\
$1980-1985$ & 415.64 & 3.3076 & 0.00768 \\
$1985-1990$ & 486.78 & 3.1351 & 0.01198 \\
$1990-1995$ & 479.72 & 6.6624 & -0.00314 \\
$1995-2000$ & 520.7 & 6.072 & -0.01 \\
$2000-2005$ & 469.74 & 4.9622 & -0.0207 \\
\hline
\end{tabular}

\subsection{Entropy Evolution to Artificial Recharge}

As discussed above, groundwater withdrawal is the main driving force for the information entropy variation of the groundwater flow system, and in order to decrease the cone of depression in Shijiazhuang City, water was transferred from a thousand kilometers away (Han River, a branch of Yangtze River); the transferred water would be recharged into the local shallow aquifer as artificial recharge for local water resources management.

In order to evaluate the impacts of artificial recharge, a groundwater flow simulation model based on the Groundwater Modeling System (GMS) software was used to predict groundwater level variations under different extreme weather conditions [11]. The concept of the hydrogeological model has been discussed in detail [11]. With extreme scarcity conditions, the precipitation has been set as $312.4 \mathrm{~mm}$ per year during the prediction period, and the precipitation as $720.2 \mathrm{~mm}$ per year during the prediction period under extreme abundance conditions. The two types of precipitation can be calculated based on historical precipitation data, and the frequency of scarce conditions has been set as $87.50 \%$ and the frequency of abundant conditions as $12.50 \%$. The extreme precipitations have been applied in the evaluation of groundwater vulnerability variations under artificial recharge (as scenario 2 and scenario 3). 
The amount of artificial recharge water has been set as $4.64 \times 10^{4} \mathrm{~m}^{3}$ per year and $8.72 \times 10^{4} \mathrm{~m}^{3}$ per year, respectively, according to the extreme weather conditions in the Han River Basin (transferred water source area). Three scenarios with different weather conditions are proposed as follows (which are also discussed in detail in [20]):

Scenario 1: there is no artificial recharge with the present groundwater abstraction status. The groundwater level in 2020 could be predicted by the established groundwater simulation model as shown in Figure 3A.

Scenario 2: under scarcity conditions in both the Huangbizhuang Groundwater Reservoir (HGR) and Hanjiang Reservoir (HR), the quantity that could be used to recharge is $4.64 \times 10^{4} \mathrm{~m}^{3} / \mathrm{a}$, and the artificial recharge lasts for seven years, from 2013 to 2020, with the local groundwater level enhanced as shown in Figure 3B.

Scenario 3: under abundance conditions in both HGR and HR, and the quantity that could be used to recharge is $8.72 \times 10^{4} \mathrm{~m}^{3} / \mathrm{a}$, and the artificial recharge lasts for seven years, from 2013 to 2020 , with the local groundwater level enhanced as shown in Figure $3 \mathrm{C}$.

Figure 3. Groundwater level contour maps. (A-C) are groundwater level contour map in scenarios 1,2 and 3 , respectively.


Based on the information entropy theory, the groundwater flow system information entropy could be calculated based on the prediction results in Figure 3, and the results are seen in Figure 4. From the figure we can see that, the information entropy decreased until 2020 under scenario 1 without artificial recharge, and that of scenario 2 and scenario 3 increased with the artificial recharge.

According to the artificial recharge water quantities and the increased entropy, the doubled water recharged from scenarios 2 to scenario 3 does not make the rate of information entropy increase double, which means that a smaller recharge water would enhance the information entropy drastically, but then a doubled water quantity would not increase the information correspondingly. As the groundwater storage reservoir is not a closed tank, recharged water could be discharged to the adjacent area, which mean that, if the recharge water doubled, the stored water would not be doubled as part of it is discharged to adjacent areas, and the more water recharged, the higher the percentage of water discharged, and the groundwater system entropy also does not increase by double. 
From the discussion above, we can see that information entropy could be used in groundwater flow system evolution analysis, and the results could be used to assess the groundwater flow system health state.

Figure 4. Information entropy prediction based on numerical simulation results.

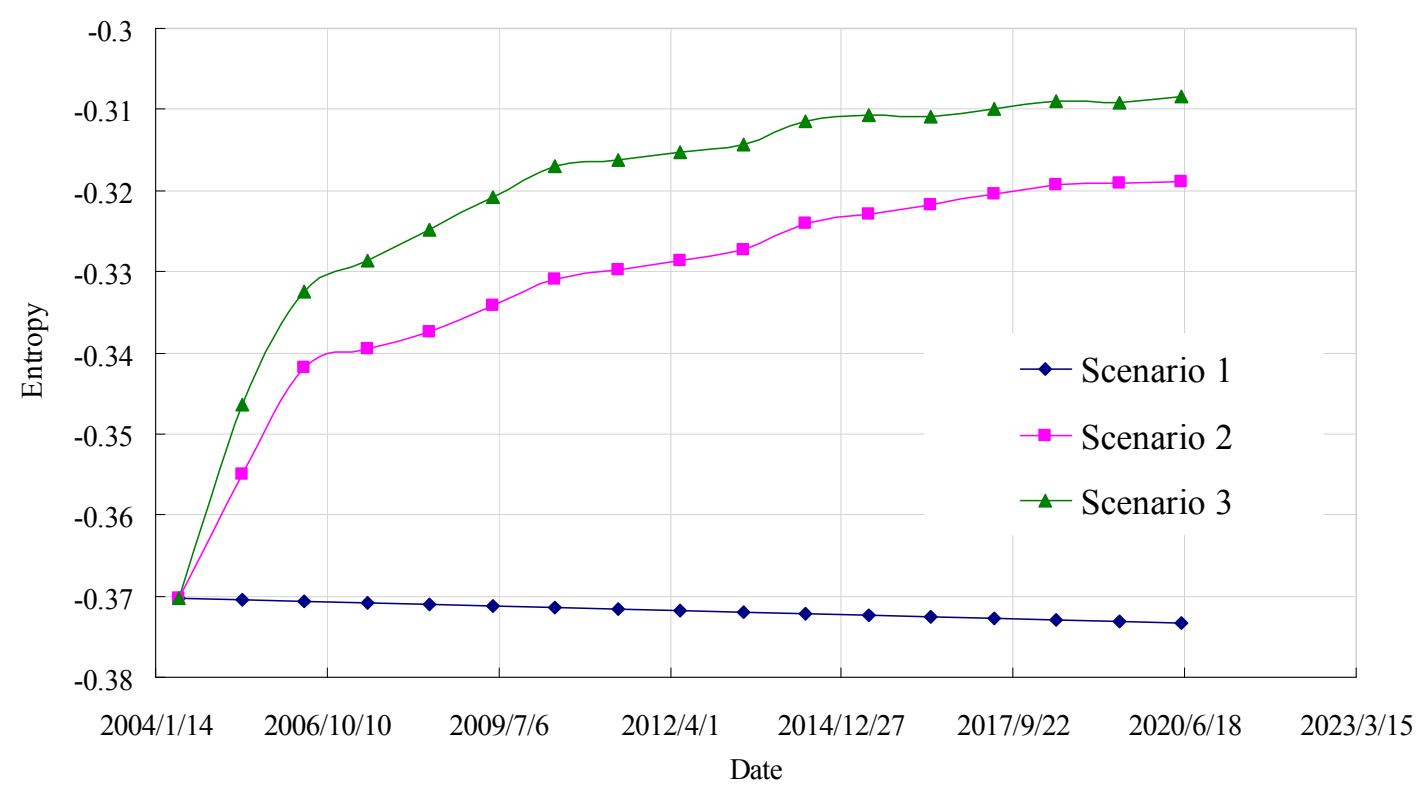

\section{Conclusions}

(1) Groundwater flow systems have typical characteristics of dissipative structures, and their evolution can be described by information entropy, entropy input from the environment and the internal system entropy variation determines the direction of groundwater flow system evolution;

(2) Groundwater system entropies generally showed a decreasing trend in Shijiazhuang City, where the entropy variation of the groundwater flow systems can be divided into four stages: steady entropy period (1960-1965), decreasing entropy period (1965-1980), increasing entropy period (1980-1995) and second entropy decreasing period (1995-2005);

(3) The correlation grade between groundwater flow system information entropies and precipitation is $\gamma_{01}=0.749$, the correlation grade between groundwater flow system information entropies and groundwater withdrawal is $\gamma_{02}=0.814$, as groundwater excavation is the main driving force of groundwater system entropy variation;

(4) Based on the numerical simulation results, information entropy increased with artificial recharge, and a smaller recharge water volume would enhance the information entropy drastically, but then doubling the water would not increase the information correspondingly, which could be useful to assess the health state of groundwater flow systems.

(5) This study attempts to connect the information entropy theory and groundwater flow system and perform a preliminary exploration to explain the meaning of groundwater flow system entropy. It should be firmly believed that groundwater flow systems can be described with information entropy language, which should be useful for groundwater resource evaluation and management. 
Future study should focus on the meaning of internal entropy and total entropy of the groundwater flow system, the factors should be investigated to know how and why the groundwater flow system entropy changed, which how it could be useful to assess the groundwater flow system state and take groundwater resources management measures.

\section{Author Contributions}

Wei Xu and Shanghai Du both designed and wrote the paper. Both authors have read and approved the final manuscript.

\section{Conflicts of Interest}

The authors declare no conflict of interest.

\section{References}

1. Ma, J.H.; Guan, H. System Science and Its Application in Geography; Science Publisher: Beijing, China, 2003. (In Chinese)

2. Xu, J.H.; Gao, Y.J. The self-organizing way, influencing factors and entropy change of geographical system evolution. J. Syst. Dialectic. 2001, 3, 53-57.

3. Ai, N.S. Comentropy in erosion drainage system. J. Soil Water Conserv. 1987, 2, 1-8. (In Chinese)

4. Shen, W. The theory of self-organization and dissipative structures and its application in geology. Geol.Geochem. 2001, 3, 1-6. (In Chinese)

5. Chan, J.X.; Huang, Q.; Wang, Y.M. Water resources evolution direction distinguishing model based on dissipative structure theory and gray relational entropy. J. Hydraul. Eng. 2002, 11, 107-112. (In Chinese)

6. Guan, X.G. Dialectic of System evolution: The integer of Dissipative structure theory. J. Syst. Dial. 1999, 2, 12-15. (In Chinese)

7. Jiang, J.Y.; Cao, J.F.; Li, S.; Wang, B. Analysis on the Evolution of Groundwater System Using the Theory of Dissipative Structure. Res. Soil Water Conserv. 2007, 72-74. (In Chinese)

8. Jiang, J.Y.; Zhang, Y.D.; Gu, H.B. Study on the Evaluation Model of Groundwater Environment Evolution Pattern Based on Grey Correlation Entropy. J. Jilin Univ. (Earth Sci. Ed.) 2009, 6, 1111-1116. (In Chinese)

9. Zhang, G.H.; Fei, Y.H.; Zhang, X.N. Abnormal variation of groundwater flow field in plain area of Hutuo River basin and analysis on its cause. J. Hydraul. Eng. 2008, 6, 747-752. (In Chinese)

10. Fei, Y.H.; Miao, J.X.; Zhang, Z.J. Analysis on Evolution of Groundwater Depression Cones and Its Leading Factors in North China Plain. Resour. Sci. 2009, 3, 394-399. (In Chinese)

11. Du, S.; Su, X.; Zhang, W. Effective storage rates analysis of groundwater reservoir with surplus local and transferred water used in Shijiazhuang City, China. Water Environ. J. 2013, 27, 157-169.

12. Yu, H.L.; Chu, H.J. Understanding space-time patterns of groundwater system by empirical orthogonal functions: A case study in the Choshui River alluvial fan, Taiwan. J. Hydrol. 2010, $381,239-247$. 
13. Deng, J.L. Fundamental Methods on Grey System; Hua-Zhong University of Science and Technology Press: Wuhan, China, 1996. (In Chinese)

14. Chang, N.B. Sustainable water resources management under uncertainty. Stoch. Environ. Res. Risk Assess. 2005, 19, 97-98.

15. Chang, T.C.; Lin, S.J. Grey relation analysis of carbon dioxide emissions from industrial production. J. Environ. Manag. 1999, 56, 247-257.

16. Liang, R.H. Application of grey relation analysis to hydroelectric generation scheduling. Int. J. Electr. Power Energy Syst. 1999, 21, 357-364.

17. Fung, C.P. Manufacturing process optimization for wear property of fiber reinforced polybutlene terephthalate composite with grey relation analysis. Wear 2003, 254, 298-306.

18. Yeh, Y.L.; Chen, T.C. Application of grey correlation analysis for evaluating the artificial lake site in Pingtung Plain, Taiwan. Can. J. Civil Eng. 2004, 31, 56-64.

19. $\mathrm{Su}, \mathrm{X}$.; $\mathrm{Xu}, \mathrm{W}$; $\mathrm{Du}, \mathrm{S}$. In situ infiltration test using a reclaimed abandoned river bed: managed aquifer recharge in Shijiazhuang City, China. Environ. Earth Sci. 2014, 71, 5017-5025.

20. Su, X.; Xu, W.; Du, S. Responses of groundwater vulnerability to artificial recharge under extreme weather conditions in Shijiazhuang City, China. J. Water Supply Res. Technol.-Aqua 2014, 63, 224-238.

21. Shannon, C.E.; Weaver, W. The Mathematical Theory of Communication; University of Illinois Press: Champaign, IL, USA, 1949.

22. Strahler, A.N. Hypsometric (area-altitude) analysis of erosional topography. Geol. Soc. Am. Bull. 1952, 63, 1117-1142.

23. Gau, H.S.; Hsieh, C.Y.; Liu, C.W. Application of grey correlation method to evaluate potential groundwater recharge site. Stoch. Environ. Res. Risk Assess. 2006, 20, 407-421.

24. Zeng, X.K.; Wang, D.; Wu, J.C. Sensitivity analysis of the probability distribution of groundwater level series based on information entropy. Stoch. Environ. Res. Risk Assess. 2012, 26, 345-356.

25. Zhai, Y.; Guo, Y.; Zhou, J.; Guo, N.; Wang, J.; Teng, Y. The spatio-temporal variability of annual precipitation and its local impact factors during 1724-2010 in Beijing, China. Hydrol. Processes 2014, 28, 2192-2201.

26. Chen, M.X.; Ma, F.S. Groundwater Resources and Environment in China; Earthquake Publisher: Beijing, China, 2002.

(C) 2014 by the authors; licensee MDPI, Basel, Switzerland. This article is an open access article distributed under the terms and conditions of the Creative Commons Attribution license (http://creativecommons.org/licenses/by/3.0/). 